\title{
The Necessity of Validated Questionnaires: Determining Accurate Responses to Proton Pump Inhibitor Use
}

TO THE EDITOR: The paper of Dickman et $\mathrm{al}^{1}$ showed interesting results that patients refractory to proton pump inhibitors (PPI) showed atypical gastroesophageal reflux disease (GERD) symptoms, disease duration and severity, Helicobacter pylori status, and obesity. They investigated the patients' compliance to medication, the presence of atypical GERD symptoms, and the patients' responsiveness to PPI. However, it is not certain whether the questionnaires that they have used were well-validated or not. Questionnaires like GERD-Q or Mayo Dysphagia Quesionnaire-30 days are known to be fully validated after the confirmation of reproducibility. Consequently, fully validated questionnaires would be better in detecting significant differences among the success and failure of groups taking PPI once or twice per day. ${ }^{2-4}$ In addition to the questionnaire, patients were retrospectively asked about their medication compliance, and verification of that compliance was based solely on the patients' words. More objective methods, such as checking the remaining number of PPI tablets, might be a more reasonable and precise method to determine the compliance rather than relying on the patients' replies to the question. As a result of this bias, the assessment of patients' response to the medication might be too subjective and it may not reflect the true effect to medication itself. Moreover, the design of this study did not involve the concomitant use of double blind, placebo medication. Therefore, the patients who answered that they were responsive to PPI might have been experiencing a significant placebo effect. To overcome those limitations, the use of well-validated questionnaires might be needed in this study.

Kee Wook Jung

Asan Digestive Disease Research Institute Department of Gastroenterology University of Ulsan College of Medicine Asan Medical Center, Seoul, Korea

1. Dickman R, Boaz M, Aizic S, Beniashvili Z, Fass R, Niv Y. Comparison of clinical characteristics of patients with gastroesophageal reflux disease who failed proton pump inhibitor therapy versus those who fully responded. J Neurogastroenterol Motil 2011;17: 387-394.

2. McElhiney J, Lohse MR, Arora AS, et al. The Mayo Dysphagia Questionnaire-30: documentation of reliability and validity of a tool for interventional trials in adults with esophageal disease. Dysphagia 2010;25:221-230.

3. Grudell AB, Alexander JA, Enders FB, et al. Validation of the Mayo Dysphagia Questionnaire. Dis Esophagus 2007;20:202-205.

4. Jones R, Junghard O, Dent J, et al. Development of the GerdQ, a tool for the diagnosis and management of gastro-oesophageal reflux disease in primary care. Aliment Pharmacol Ther 2009;30:10301038 .

\section{Conflicts of interest: None.}

